\title{
Metateoretiese vertrekpunte ten opsigte van wetenskaplike navorsing in kinder- en jeugbediening
}

\author{
Author: \\ Gert Breed ${ }^{1}$ \\ Affiliation: \\ ${ }^{1}$ School for Ecclesiastical \\ Sciences, North-West \\ University, South Africa \\ Correspondence to: \\ Gert Breed \\ Email: \\ gert.breed@nwu.ac.za \\ Postal address: \\ PO Box 19515, Noordbrug \\ 2522, South Africa \\ Dates: \\ Received: 08 Aug. 2013 \\ Accepted: 08 Feb. 2013 \\ Published: 11 July 2013 \\ How to cite this article: \\ Breed, G., 2013, \\ 'Metateoretiese \\ vertrekpunte ten opsigte van \\ wetenskaplike navorsing in \\ kinder- en jeugbediening', \\ In die Skriflig/In Luce Verbi \\ 47(1), Art. \#579, 11 pages. \\ http://dx.doi.org/10.4102/ \\ ids.v47i1.579

\section{Copyright:} \\ C 2013. The Authors. \\ Licensee: AOSIS \\ OpenJournals. This work \\ is licensed under the \\ Creative Commons \\ Attribution License.
}

Read online:

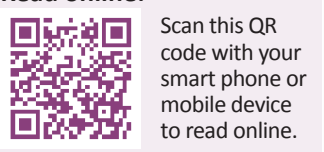

Hierdie artikel vorm deel van 'n navorsingsprojek oor die verrekening van die metateoretiese vertrekpunte in die wetenskap van die Praktiese Teologie. Die eerste fase van die reeks bied die teoretiese onderbou vir die werklikheids-, hermeneutiese en wetenskapsteoretiese beskouing van die vak. Die tweede fase fokus op die invloed wat hierdie vertrekpunte op die wetenskaplike navorsing van die verskillende vakgroepe in die Praktiese Teologie het. Hierdie artikel handel oor die wetenskaplike benaderingswyse tot die navorsingsveld van Kinder- en jeugbediening. In hierdie navorsingsartikel word die persoonlike metateoretiese perspektief waarmee die vakgebied van Kinder- en jeugbediening benader word, uitgespel en verantwoord ten opsigte van die werklikheidsbeskouing waarmee daar op die navorsingsveld van Kinder- en jeugbediening gefokus word; die onderbou van die hermeneutiese beskouing wat nodig is om tot ' $n$ verstaan en 'n verantwoordbare verhouding te kom tussen die elemente wat in Kinderen jeugbediening ter sprake is; en ten slotte, om die wetenskapsteoretiese benadering te beskryf waarmee die navorsingsveld van Kinder- en jeugbediening op ' $n$ wetenskaplikverantwoorde wyse ondersoek kan word.

Metatheoretical assumptions in scientific pastoral-theological research regarding child and youth ministry. This article is part of a research project on the metatheoretical assumptions in Practical Theology. The first part of this series gives the theoretical foundation for the view on reality-, hermeneutical- and scientific-theoretical approaches to the research field. The second part focuses on the effect that these assumptions will have on the scientific research of the various subject groups in Practical Theology. This article describes the scientific approach to the research field of child and youth ministry. This research article describes the personal metatheoretical perspective from which the subject area is approached, and it gives account of the view on reality with which the research field of Youth Ministry is studied; of the foundation on which the hermeneutical viewpoint is built, to attain an understanding and a founded relationship between the elements that are applicable in child and youth ministry; and finally, the scientific theoretical approach to the research field in a justified manner.

\section{Inleiding}

Hierdie artikel is deel van 'n navorsingsprojek oor die verrekening van die metateoretiese vertrekpunte in die wetenskap van die Praktiese Teologie. Die eerste fase van hierdie reeks artikels bied die teoretiese onderbou vir die werklikheids-, hermeneutiese en wetenskapsteoretiese beskouing van die vak. Die tweede fase van die navorsing fokus op die invloed wat hierdie vertrekpunte op die wetenskaplike navorsing van die verskillende vakgroepe in die Praktiese Teologie het. Hierdie artikel handel oor die wetenskaplike benaderingswyse tot die navorsingsveld van Kinder- en jeugbediening.

Kinder- en jeugbediening ${ }^{1,2}$ is die dienswerk $\left(\right.$ diakonia $\left.^{3}\right)$ van die kerk aan 'n besondere deel van die liggaam van Christus. Dat dit ' $n$ legitieme vertrekpunt is om navorsing oor ' $n$ bepaalde segment van die gemeente te doen, kan onder andere uit 1 Korintiërs 12 afgelei word. In 1 Korintiërs 12 word die eenheid en die verskeidenheid van die liggaam van Christus gevier (Vos 1993:260; Collins \& Harrington 1999:449; Breed 2012a:5) Daar is 'n verskeidenheid gawes en 'n verskeidenheid bedienings wat saamgebind word deur elke lid se verbondenheid aan Christus en die feit dat elke lid in die liggaam nie toevallig daar is nie, maar deur God daar geplaas is om 'n bepaalde funksie

1.Die studie word gedoen binne die perspektief van die klassieke gereformeerde ensiklopedie.

2.Die onderskeid tussen kinderbediening (1-12 jaar) en jeugbediening (12-18 jaar) sal in hierdie artikel gebruik word. Daar word egter nie op die substansiële verskille in die praktyk van hierdie twee bedienings ingegaan nie, aangesien die vooronderstellings dieselfde is, al is die toepassing daarvan tot 'n groot mate verskillend.

3.Diakonia word in hierdie artikel verstaan in die lig van die nuutste navorsing oor die betekenis van die diakon-woordgroep in die Nuwe Testament (vgl. Noordegraaf 1991:12, 13; Hayler 2006:1; Breed \& Breed 2010:636, 637; Sell 2010:60; Breed 2012a:1-3). Volgens hierdie navorsing beskryf die spesifieke woordgroep die totale bediening van die gemeente en daarom is kinder- en jeugbediening deel van die volle diakonia van die gemeente. 
(diakonia) te vervul. Die Gees gee aan elkeen 'n besondere gawe vir die besondere diens (diakonia) wat hulle moet vervul. Die liggaam word verder deur die lede se onderlinge betrokkenheid by mekaar se wel en weë saamgebind. Die lid wie se behoefte die grootste is, moet meer versorging ontvang (Berding 2006:105; Hastings 2007:33.) Met hierdie beeld word die eervolle plek van die kinders en die jeug binne die gemeente deur God se Woord vasgelê. Die feit dat kinders en die jeug op 'n unieke manier geestelik kwesbaar en materieel afhanklik is, plaas hulle volgens 1 Korintiërs 12:24 in 'n posisie binne die liggaam waar hulle besondere sorg moet ontvang (Berding 2006:105; Hastings 2007:33). Die feit dat elkeen van hulle met besondere gawes vir die besondere diakonia deur God in die liggaam gestel is, plaas die roeping op die kerk om hulle die geleentheid te bied om hulle roeping uit te leef. Omdat die kinders en jongmense ook lede van die liggaam is, behoort hulle ' $n$ integrale deel van die bediening van die gemeente te vorm (Bunge 2008:352, 353, 356, 357).

Daar bestaan 'n ryke verskeidenheid benaderings tot jeugbediening (Strommen \& Hardel 2008:16-17; Senter 2010:35-37). Elke benadering is op bepaalde vooronderstellings gegrond. Elke benadering het 'n bepaalde einddoel voor oё ${ }^{4}$ (Dreyer 2004:11). Dean et al. (2010:8) vra of die doel van kinder- en jeugbediening is om dissipels van Christus toe te rus ' $[o] r$ does it cultivate interpersonal niceness, social acceptability, civic engagement, and - as primary goal - church membership?' [of kweek dit interpersoonlike vriendelikheid, sosiale aanvaarbaarheid, gemeenskapsbetrokkenheid en as primêre doel - kerklidmaatskap?]. DeVries (2008:10) sê dat hy in sy betrokkenheid by 'n verskeidenheid kerke se beplanning van hulle kinder- en jeugbediening 'n patroon sien ontvou het, naamlik dat die meeste kerke se bediening op raaiwerk geskoei is: 'Most churches have chosen to do youth ministry with a model best described as gambling.' [Die meeste kerke kies om jeugbediening te doen aan die hand van 'n model wat die beste beskryf kan word as 'n dobbelspel]. Die jeugbediening word op die een goeie wenk na die ander gebaseer, wat egter almal op kitssukses gemik is.

Die vooronderstellings van die navorser of gemeente bepaal die vertrekpunte van die kinder- en jeugbediening of die navorsing. Hierdie vertrekpunt bepaal die doel, die metodiek en die inhoud van die jeugbediening (Newport 1998:40); De Wet \& Pieterse 2010:528). Wanneer 'n bepaalde jeugbediening op vaste beginsels of vooronderstellings gegrond is, word dit daardeur gerig en word willekeur daardeur vermy (Robbins 2004:16-39). Daarom is dit so belangrik dat die vooronderstellings, gegrond op die Woord, duidelik vir reformatoriese kinder- en jeugbediening uitgespel moet word (Richards 1983:11, 12).

Hierdie navorsingsartikel het ten doel om eie reformatoriesmetateoretiese vertrekpunte ten opsigte van kinder- en jeugbediening te probeer formuleer.

4.Vir die bespreking van die benaderings van Browning, Dingemans, Heitink en Osme ten opsigte van vooronderstellings, vergelyk ' $n$ vorige artikel in hierdie projek (Pieterse 2011:731-735)
Vir hierdie doeleindes word van Osmer (2008:58) se definisie gebruik gemaak om die elemente te bepaal waaruit 'n metateorietiese perspektief saamgestel is: 'A metatheoretical perspective, thus is composed of the assumptions about reality, knowledge and science that transcends particular research projects and theories.' ['n Metateoretiese perspektief is dus saamgestel uit die vooronderstellings ten opsigte van die werklikheid, kennis en wetenskap wat wyer as die spesifieke navorsingsprojekte en teorieë geldig is.] In die eerste vier artikels van hierdie navorsingsprojek is breedvoerig op die leemtes ingegaan wat ten opsigte van die metateoretiese verantwoording in die navorsing bestaan asook die noodsaak van 'n reformatoriese verantwoording oor die eie vooronderstellings, gevolglik sal daar nie nou weer daarby stilgestaan word nie.

In die loop van hierdie navorsingsartikel word die eie metateoretiese perspektief waarmee die vakgebied van Kinderen jeugbediening benader word, uitgespel en verantwoord ten opsigte van die volgende:

- werklikheidsbeskouing waarmee daar op die navorsingsveld van Kinder- en jeugbediening gefokus word;

- onderbou rakende die hermeneutiese beskouing wat nodig is, om tot ' $n$ begrip en ' $n$ verantwoordelike inrigting te kom van die verhouding tussen die kommunikatiewe elemente wat in kinder- en jeugbediening ter sprake kom; en

- die wetenskapsteoretiese benadering waarmee die navorsings-veld van Kinder- en jeugbediening op 'n wetenskaplikverantwoorde wyse ondersoek kan word (De Wet \& Pieterse 2010:486, 487).

\section{Vooronderstellings in die werklikheidsbeskouing ${ }^{5}$}

Wanneer die mens met die omringende werklikheid in aanraking kom, moet met daardie werklikheid in gesprek getree en dit geïnterpreteer word om vir jouself oortuigings te vorm waarvolgens jy binne hierdie werklikheid kan leef en oorleef (Colson \& Pearcy 1999:ix.; Wolters 2005:2-5) Die mens moet ook God se verhouding tot jouself en die werklikheid deurdink en tot bepaalde oortuigings kom wat medebepalend gaan wees vir jou optrede binne die werklikheid (Dingemans 1996:133). Elke mens vorm hierdie oortuigings op 'n voorwetenskaplike, byna onbewustelike wyse (De Wet 2011:3). Reformatoriese navorsers behoort op wetenskaplike wyse hulleself te verantwoord oor hulle eie vooronderstellings ten opsigte van die werklikheid, God se verhouding tot die werklikheid en die rol van die Bybel in die bestudering van die werklikheid. Hulle behoort ook ander beskouings van die werklikheid wat hulle bestudeer ernstig op te neem en hulle eie vooronderstellings oop te stel vir kritiek (vgl. Barrett 2000:308).

Die vraag wat in hierdie deel van die artikel beantwoord moet word, is hoe die reformatoriese navorser die werklikheid sien waarin die kind bedien moet word.

5.Vergelyk' n vorige artikel (De Wet 2011) in hierdie navorsingsprojek vir'n indringende bespreking van die noodsaak daarvan om metateoretiese vertrekpunte ten opsigte van die werklikheidsbeskouing in praktiesteologiese wetenskapsbeoefening uit te spel. 


\section{Die kinders en jongmense moet deur die volk van God ${ }^{6}$ bedien word}

Dat die kinders en jongmense bedien moet word is, reeds hierbo bespreek. 'n Mens sou egter ook na talle ander Skrifgedeeltes kon verwys ter bevestiging van die opdrag aan die volk van God om die kinders en jongmense te bedien (Marty 2007:86). Deuteronomium 6 is een van die bekendstes waar ouers die opdrag kry om die kinders in die voorskrifte van die Here te onderrig; so ook Psalm 78. In Hebreërs 12 word van die veronderstelling uitgegaan dat vaders hulle kinders tugtig na hulle beste wete (vers 10) en in Efesiërs 6:4 word die vaders vermaan om hulle kinders in die tug en vermaning van die Here op te voed. In Psalm 103:13 word die verhouding tussen vader en kind beskryf met die woord racham, wat as liefdevolle versorging (ontferming) deur die vader verstaan kan word. Dit moes vir die Israeliete 'n besondere troosvolle verhouding uitgebeeld het, omdat die digter dit gebruik om God se optrede te beskryf wanneer Hy ons nie volgens ons sondes straf nie (vers 12), maar sy optrede laat bepaal deur sy kennis van ons swakheid (vers 14-16). Die liefdevolle onderrig aan die kinders en jongmense word in die boek Spreuke beskryf (vgl. DeVries 2008:141144; Tripp 1997:76, 81-83). Kinders en jongmense mag nie slegs as individue bedien word nie, maar eerder as deel van die liggaam van Christus. Die huidige ooraksentuering van die individu verarm die bediening van die kerk (Purves 2004:211-213)

Hierdie vooronderstelling sal in die navorsing oor gemeentebediening daartoe aanleiding gee dat die liefdevolle bediening van die jongmens en die kind medebepalend sal wees vir die uitkomste van die navorsing.

\section{Kinders en jongmense is leerlinge}

Die beeld van kinders en jongmense as leerlinge kan uit verskillende Skrifgedeeltes afgelei word. In Hebreërs 5:13 word die baba as onvolwassene geteken wanneer die gemeente met babas vergelyk word, omdat hulle nie gegroei het in hulle geloofsvolwassenheid nie. Die groei vind deur inoefening plaas en deur middel van ervaring (Ef 5:14). In Efesiërs 6 word ektrefo gebruik om die ouers se taak ten opsigte van die opvoeding van hulle kinders te beskryf. Ektrefo beteken om te koester sowel as om groot te maak. Hierdie opvoeding moet plaasvind deur paideia en nouthesia. Paideia dra waarskynlik die betekenis van inoefening (training) met die klem op aktiwiteit en nouthesia dra waarskynlik die betekenis van vermaning en reghelp wanneer jy verkeerd doen, met die klem op verbale onderrig (Hoehner 2002:798). Kinders word ook hier geskets as leerlinge wat op 'n regverdige wyse behandel behoort te word sodat die opvoeding nie bitterheid by hulle wek nie. Richards (1983:20-24) toon aan dat alhoewel daar in die Ou Testament nie sprake was van afsonderlike strukture vir die bediening van kinders en die jeug nie, was onderrig van kinders en die jeug 'n integrale deel van die samelewing, '... for the whole fabric of the divinely planned society is essentially educational' [... aangesien die hele ander gelowiges wat by die kinders en jeug betrokke is, te beskryf. struktuur van die goddelik-beplande samelewing hoofsaaklik opvoedkundig was] (Richards 1983:20).

Sowel uit die $\mathrm{Ou}$ as die Nuwe Testament kan afgelei word dat deelname ' $n$ kragtige en noodsaaklike instrument in die toerusting van kinders en jongmense is (Breed 1994:105-132). Een van die voorbeelde uit die Ou Testament is die deelname van die kinders aan die Pasga (vgl. Breed 1996). Die kinders was deel van die volksvergaderings waar daar uit die Woord onderrig is (Neh 8). In Efesiërs 4 word gesê dat elkeen in die gemeente gawes ontvang het en toegerus behoort te word om hulle dienswerk (diakonia) te verrig. Die skrywer van die brief praat in sy brief direk met die kinders as deel van die gemeente (Ef 6:1, 2; vgl. Grobbelaar 2008:371,372) en daarom kan aanvaar word dat die kinders en die jeug ook aan die diakonia van die gemeente moes deelneem (Ef 4). Hiervoor moes hulle doelgerig toegerus word (Robbins 2004:446-451). Wanneer kinders en jongmense aan die bediening in die gemeente deelneem, identifiseer hulle met die gemeente en met God, of hulle kom tot die oortuiging dat hulle nie deel van die gemeente wil wees nie; hulle kan egter nie neutraal bly nie (Smith 2005:60, 61).

Saam met toerusting deur deelname gaan ook die belangrike klem wat die Bybel op rolmodelle plaas. Paulus stel homself herhaaldelik as rolmodel voor die gemeente (Veerman 1997:218-238). Jesus se skerpste verwyt aan die godsdienstige leiers van sy tyd was dat hulle nie rolmodelle vir die volk was nie, maar dat hulle swaar laste op die volk se skouers geplaas het wat hulleself nie kon verroer nie (Matt 23:4). Strommen en Hardel $(2008: 179,226,264)$ toon vanuit empiriese navorsing die belangrikheid aan van meer rolmodelle vir geloofsgroei vir die kinders en die jongmense. Paulus beskryf homself as rolmodel in sy liefde, ywer en ontferming oor die gemeente (1 Tess 2; vgl. ook Purves 2004:193-205). Robbins (2004:474-275) beklemtoon dat die rolmodelle vir kinders en jongmense bereid moet wees om van hart tot hart met ander kontak te maak en in staat moet wees om met insig en fyn aanvoeling die diepste gevoelens en verlangens van die jongmense te verwoord. 'n Rolmodel moet ook vol begrip en ontferming wees. Om dit te kan wees, moet rolmodelle bereid wees om na kinders en jongmense te luister en 'n omgewing te skep waar daar vrymoedigheid is om openlik oor moeilike onderwerpe te gesels, met mekaar te verskil en biddend na antwoorde te soek (vgl. ook Strommen \& Hardel 2008:138; Blount 2005:7; DeVries 2008:152-155).

Vir navorsing uit 'n reformatoriese perspektief sal die betrokkenheid van kinders en jongmense by die erediens en hulle integrering in die totale gemeentebediening bepalend wees vir die inrigting van die kinder- en jeugbediening. Elke faset van die gemeentebediening waarby kinders en die jeug betrokke is, sal in ag moet neem dat daar vir hulle groei as leerders saam met volwasse rolmodelle voorsiening gemaak moet word. Navorsing behoort te ondersoek hoe hierdie vooronderstelling die bedieningsplan van die gemeentes behoort te beïnvloed (DeVries 2008:57-73). Hiermee word bedieningsprogramme waarvan die doel hoofsaaklik of uitsluitlik vermaak is, uitgesluit (vgl. Senter 2010:307; Dean et al. 2010:1-3). 


\section{Kinder- en jeugbediening is op gesonde gesinne gegrond}

'n Bedieningsplan van 'n gemeente behoort elke faset van die bediening ten volle met die totale bediening te integreer (Vukich \& Vandegriff 2002:212). Gesinsbediening mag ook nie losstaan van kinder- en jeugbediening nie (Dean et al. 2010:8). Die werklikheid is dat die tyd wat kinders en jongmense aktief in die gemeente bedien word, beperk is. Volgens Deuteronomium 6 vind die inskerping en die praktykmaking van God se waarheid binne die gesin plaas waar hulle van dag tot dag die werklikheid van die lewe moet hanteer. Elke gemeente behoort toerusting aan gesinne te gee wat hulle vir die uitdagings toerus waarmee hulle van dag tot dag gekonfronteer word. By gesinsbediening is huweliksverryking ingesluit (Bunge 2008:350). Die ouers se verhouding met mekaar het 'n direkte invloed op die kinders en jongmense se vrede en vreugde en daarom ook hulle bevatlikheid vir geloofsgroei. Navorsing oor kinder- en jeugbediening moet gesinsbediening as 'n prioriteitsnavorsingsveld ontgin (Mueller 2007:41-48).

\section{Kinder- en jeugbediening neem die verbond van God as vertrekpunt}

Bediening van die jeug en deur die jeug is alleen moontlik omdat elke gelowige in Christus deel gekry het aan die verbondsbeloftes wat aan Abraham gegee is. God het deur die verbondsluiting met Abraham en die vervulling daarvan in Christus ' $n$ noue persoonlike verhouding met Homself moontlik gemaak (Van der Merwe 2004:27-29). Hy het sy Gees uitgestort sodat die Woord effektief bedien kan word en mense tot geloof kan kom en deel kan word van die verloste volk van God, sodat hulle saam met die volk tot geloofsvolwassenheid kan groei (Ef 2 en 4 ). Vir reformatoriese navorsers is die verbond ' $n$ werklikheid wat bepalend is in hulle benadering tot jeugbediening (Richards \& Martin 1981:27-41). Die kind moet benader word as iemand wat 'n teken en seël van God ontvang het dat sy beloftes ook vir die kind geldig is. Elke aksie is daarop gemik om die jongmens sekerheid van en insig in hierdie besondere verhouding met God te gee. Jongmense word dus nie bloot in 'n bepaalde moraliteit geskool nie, maar word begelei om op die liefde van God te antwoord asook op die toesegging van genade soos dit in die doop beteken en verseël is (De Wet \& Breed 2012).

Jeugbediening is Woordbediening, maar spesifiek biddende bediening; biddend dat die Gees die nuwe lewe in elke kind sal werk. Jeugbediening is begeleiding tot die maak van 'n keuse om die toegesegde genade van die verbond vir die self toe te eien (Van der Merwe 2004:56-68; Dean et al. 2010:9)

Wanneer God in die doop aan die kind sy genade in beloftes toesê, bevestig Hy ook daarmee die werklikheid dat hierdie kind deel is van die volk van God, omdat sy gesin ook deel is van die volk. Anderson (2007:176) bespreek die betekenis daarvan dat die kerk 'n familie van families is. Hy beklemtoon egter ook dat die kerk 'n nuwe gemeenskap vorm (Anderson 2007:181). In Markus 3:33-35 sê Jesus dat diegene wat Hom noue band tussen die gelowiges beskryf en in 1 Johannes
4 word liefde vir mekaar as noodsaaklike element van die onderlinge verhouding tussen gelowiges beskryf. In Efesiërs 2 word die tuiskoms van die nuwe gelowige binne die gemeente as huisgesin gestel. Die kinders en die jeug is nie vreemdelinge of bywoners in die huis van God nie, maar lede van die huisgesin waar hulle opgebou kan word as tempels van die Gees (Ef 2:19-22; Kruger 2005:529-551). Navorsing oor jeugbediening moet besig wees met die vraag hoe hierdie waarheid vir elke kind 'n werklikheid gemaak kan word; hoe die atmosfeer en gesindheid in die jeugbediening en die gemeente sodanig kan wees dat kinders ervaar dat hulle deel is daarvan en daarom daar hoort. Die kerk en die jeugbediening moet ' $n$ plek van warmte, liefde en tuiskoms wees (Breed 1994:212 213). Dit moet 'n plek wees van onvoorwaardelike aanvaarding en vergifnis waar die berouvolle sondaar tot volharding op die weg van Christus begelei word (DeVries 2008:74-89).

Die verbond het ook ten diepste met identiteit te make. Elke kind in die groeiproses na volwassenheid worstel met die vraag: 'Wie is ek?'. Hierdie vraag word dikwels beantwoord in die lig van die antwoord op 'n ander vraag, naamlik 'waar behoort ek?'. Jongmense laat hulleself in hulle eie oortuigings definieer deur die groep maats waaraan hulle behoort, of die sportspan waarvan hulle deel is of nie deel is nie, of die akademiese prestasie wat hulle behaal. Wanneer 'n mens se identiteit bepaal word deur iets wat van jou weggeneem kan word, kan die gedagte aan daardie verlies soveel druk op jou plaas dat jy baie kosbare dinge sal verruil vir die voorreg om deelwees te behou (Robbins 1990:73; Vukich \& Vandegriff 2002:145-161). Blount (2005:2,3) sê dat die vraag 'Who am I?' [Wie is ek?] vervang moet word met die vraag 'Whoose am I?' [Aan wie behoort ek?]. Dean et al. (2010:10) vra die volgende vraag: 'Do our current practices of youth ministry help young people understand themselves as Christians? Are we passing on adequate understandings of God, the church, and the world?' [Help die huidige praktyk van jeugbediening jongmense om hulself as Christene te verstaan? Leer ons hulle voldoende om God, die kerk en die wêreld te verstaan?] Die antwoord op die vraag na hulle identiteit moet kinders in hulle doop vind (De Wet \& Breed 2013:8). Volgens my word die inhoud van hierdie antwoord in die Heidelbergse Kategismus se Vraag en antwoord 1 uitgespel. Die navorser in kinder- en jeugbediening sal oor hierdie vraag moet besin om te wete te kom hoe die bediening sodanig ingerig kan word dat kinders hulle identiteit in Christus kan vind as hulle enigste troos in lewe en in sterwe (vgl. Brueggemann 2001:83).

Die verbond het verder ook te make met die opdrag om ' $n$ lig vir die nasies en 'n sout vir die aarde te wees (Jes 42:6; 49:6; Hand 13:47). God sluit sy verbond met sy kinders en realiseer dit in hulle lewe sodat hulle sy getuies in hierdie wêreld kan wees. Hierdeur kan hulle die ander skape wat tot sy kudde behoort in die kudde inbring (Joh 10). Reeder (2008) sê 'the church should gather to worship and scatter to evangelize' [die kerk moet bymekaarkom om te aanbid en uitmekaargaan om te evangeliseer] en 'our services should be primarily focused on encouraging, strengthening, and training Christians, so that they can then take the gospel to those who need to hear it' [ons 
bediening moet primêr daarop gefokus wees om te bemoedig, te versterk en Christene te onderrig sodat hulle die evangelie kan uitdra na daardie mense wat dit moet hoor]. Dit is 'n baie belangrike balans wat hier uitgespel word. Indien die kerk se jeugbediening in wese 'n evangelisasie-aksie word, bestaan die gevaar dat die verbondsjeug nie in hulle geloof in diepte en sekerheid groei nie en daarom ook nie goeie getuies kan wees nie. Die jeugbediening word dan 'n kanaal waardeur 'n groot groep jongmense invloei, maar waar die uitvloei ewe groot is (Reeder 2008:116). Indien die kinderen jeugbediening primêr op die welwees van die kinders gerig is, word hulle godsdiens 'n 'moralistic therapeutic deism' [moralisties-terapeutise deïsme] aldus Smith en Snell (2009:162-263). Hierdie outeurs som die oortuigings van hierdie godsdiens soos volg op:

- A God exists who created and orders the world and watches over human live on earth. ['n God bestaan wat die wêreld skep en onderhou en oor die mens se aardse lewe waak.]

- God wants people to be good, nice and fair to each other, as taught in the Bible and by most world religions. [God wil hê dat mense goed, vriendelik en regverdig teenoor mekaar sal wees soos in die Bybel en die meeste van die wêreldgoedsdienste geleer word.]

- The central goal of live is to be happy and to feel good about yourself. [Die hoofdoel van die lewe is om gelukkig te wees en goed oor jouself te voel.]

- God does not need to be particularly involved in one's live except when God is needed to resolve a problem. [Dit is nie nodig dat God spesifiek in iemand se lewe betrokke moet wees nie, behalwe wanneer dit nodig is dat God 'n probleem moet oplos.]

- Good people go to heaven when they die. [Goeie mense gaan hemel toe wanneer hulle doodgaan.]

Navorsing moet dus vra hoe die kinders en die jeug van die kerk begelei kan word sodat hulle ten opsigte van God se liefde:

... in staat kan wees om saam met al die heiliges ten volle te begryp wat die breedte en lengte en diepte en hoogte is, die liefde van Christus te ken wat die kennis oortref, sodat $[h]$ ulle vervul kan word met die volheid van God (Ef 3:18, 19).

Die vraag moet ook gevra word hoe hulle as koninklike priesterdom en die uitverkore volk van God sy dade kan verkondig (1 Pet 2:9) en wat die verhouding tussen hierdie twee dele van die bediening van en deur die jeug is.

\section{Verrekening van metateoretiese aspekte rakende 'n hermeneutiese benadering tot kinder- en jeugbediening}

In prakties-teologiese navorsing moet die probleem of geleentheid wat ter sprake is, begryp word. Die bybelse beginsels wat op die situasie van toepassing is, moet ontgin word en daar moet tot 'n moontlike oplossing vir die probleem gekom word, of tot die ontginning van die potensiaal van

7.Vergelyk' $n$ vorige artikel (Pieterse 2011) in hierdie navorsingsprojek wat in diepte handel oor die noodsaak van die verrekening van metateoretiese aspekte rakende 'n hermeneutiese benadering tot die Praktiese Teologie. 'n geleentheid (Pieterse 2011:728, 729). Wanneer navorsing oor kinder- en jeugbediening gedoen word, is dit belangrik dat navorsers hulself oor hulle vertrekpunte in hierdie hermeneutiese proses verantwoord. Marty (2007:1) noem dat die ontdekking van die hoe en die wat van kinder- en jeugbediening nie probleemgesentreerd behoort te wees nie, maar op die ontginning van die geheimenisvolle potensiaal van die kinders gerig behoort te wees. Jesus vergelyk die koninkryk met iemand wat saad saai en dan die geheimenis beleef van die ontkieming en groei tot rypheid sonder dat die persoon dit kan verklaar (Mark 4:26-29). Paulus druk die beperkte betrokkenheid van die menslike dienaar in die groeiproses van die geloof uit wanneer hy sê dat hy en Apollos slegs kan saai en natmaak en dat God die een is wat laat groei (1 Kor 3:6). Hierdie beelde kan ook op die hermeneutiese proses in die navorsing oor jeugbediening van toepassing gemaak word. Soos by die ontkieming en die groei van die saad, is daar ' $n$ wye verskeidenheid faktore by jeugbediening betrokke, maar dit is God se seën deur die werking van die Gees wat uiteindelik die ware sukses bepaal (vgl. Robbins 2004:1-13).

Senter (2010) beskryf die geskiedenis van die jeugbediening in Amerika, naamlik verskeie kerklike sowel as buitekerklike jeugbewegings se verloop, lewensduur, suksesse en mislukkings. Dikwels het jeugbewegings 'n bepaalde metodiek gevolg en skynbaar groot sukses behaal ten opsigte van getalle. Telkens was daar egter na 'n ruk afplatting en stagnasie. Senter (2010:298) diagnoseer die probleem ten opsigte van een van hierdie bewegings. Die metodiek wat in hierdie betrokke beweging jarelank gevolg is, was volgens die leiers op Jesus se bedieningstrategie tydens sy lewe op aarde gegrond. Toe hierdie beweging egter begin stagneer en hulle mense vra om nuut na die metodiek te kyk, is gevind dat dit nie op geldige eksegese gegrond was nie. Die probleem van die jeugbediening wat op menslike wysheid gegrond is en nie op navorsing wat die Skrif ontgin in die soeke na God se wysheid nie, kan telkens in die verskillende bewegings geïdentifiseer word as die kanker wat tot die dood van daardie jeugbediening gelei het (Richards 1983:11).

Die hermeneutiese proses moet by die navorser plaasvind ten opsigte van die samestelling van 'n bedieningsmodel en die doel, inhoud en wyse van bediening moet nagevors word. In hierdie navorsing moet insig verkry word in die bybelse beginsels wat vir jeugwerk geld; daar moet insig verkry word in die beginsels van kommunikasie soos dit van toepassing is op die verskillende ouderdomsgroepe; die grense van die verhouding tussen die persoon wat nóú met ' $n$ bepaalde groep werk, en navorsing oor geslagsgrense heen is ook nodig; die ontwikkelingsstadia van 'n kind moet begryp word en daarmee saam moet die vraag beantwoord word oor die hermeneutiese proses wat by die kind self moet plaasvind - wanneer en hoe vind die toeëiening van die beloftes van God plaas?; wat is die verhouding tussen die verskillende aspekte van jeugbediening soos georganiseerde saamwees, die onderrig uit die Woord, die georganiseerde dienswerk, evangelisasie-aksies en pastorale versorging?; hoe word kinders en jongmense in die erediens geakkommodeer 
dat die preek, 'content and encounter' [inhoud en ontmoeting] (Anderson 1964:7), 'n ontmoeting met God is. Verdere vrae wat in 'n verantwoorde hermeneutiek van kinder- en jeugbediening beantwoord moet word, is die volgende: Wat is die invloed van die huidige kulturele en sosiale stromings op die kinders en die jeug? (Benett 2011); Wat is die invloed van kontemporêre sosiale media soos Facebook, Twitter, BBM en ook televisie en internet op kinders en die jeug? (Hunt et.al. 2009); Wat is die invloed van die landsomstandigheid (korrupsie, geweld, egskeiding) op die jeug en kinders?; Watter tegnologiese hulpmiddels is beskikbaar wat in diens van die bediening gebruik kan word? (Wyn 2011); en Watter navorsing is in naasliggende vakgebiede beskikbaar wat insig in die hoe en die wat van die bediening kan bring? (Vukich \& Vandegriff 2002:19-44).

DeVries (2004:24) verskaf ' $n$ baie belangrike hermeneutiese sleutel wat by voorafgaande aansluit. Hy stel dit dat jeugbediening ' $n$ bediening in die teenwoordige tyd is, maar die toekoms in gedagte het. Jeugbediening moet die fondament lê vir die langtermyntoekoms van die kind se verhouding met God. 'n Kind kan ten volle by alle aksies van jeugbediening betrokke wees, maar dit bly 'n sosiale aksie wat ontgroei kan word. Die jeugbediening kan hierdeur 'n hindernis vir die kind wees om by God uit te kom, omdat dit 'n doel op sigself is. Die finale hermeneutiese toetssteen van jeugbediening lê in die vraag of dit die kind tot 'n ontmoeting met die drie-enige God bring en of die bediening deur die kerk, volgens die kind se ervaring, vir hom 'n bediening deur die drie-enige God is (Dean et al. 2010:6). Alleen wanneer die menslike bedienaar iewers op die agtergrond verdwyn sodat die kind alleen voor die almagtige, barmhartige en genadige God staan, kan daar 'n langtermynverhouding tussen die kind en God ontkiem. Die kind moet God ontmoet wat in sy Seun gekom het om te dien (diakoneo) en sy lewe te gee (Mark 10:45; Anderson 2001:119-121), maar ook nou van die een wat Hom wil dien (diakoneo) eis om Hom te volg in ' $n$ diensbaarheid wat bereid is om te sterwe ter wille van die dienswerk (diakonia) (Joh 12:24-26; Breed, 2012b). Slegs wanneer dit gebeur word daar 'n blywende verhouding gevestig. ${ }^{8}$ Hierdie dinamika kan alleen deur die Gees van God plaasvind. Hy openbaar die diepste geheimenisse van God aan sy kinders (Mueller 2007:418-422).

Binne 'n snelontwikkelende samelewing en kultuur is die bediening van die voortdurend-groeiende kind en jongmens 'n uitdaging wat alleen met sukses hanteer kan word deur voortdurende navorsing (Mueller 2006:58-79). Navorsing moet elke faktor (die wat hierbo bespreek is en ander wat mag ontwikkel) wat by hierdie bediening betrokke is, in die lig van die Skrif bestudeer. Die vrae wat oor die hoe en die wat van die bediening mag ontstaan, moet met eerlikheid in die oё gekyk word en na die beste van ons vermoë beantwoord word, met die wete dat die toekoms dalk ander antwoorde sal vereis op grond van dieselfde bybelse beginsels. Wanneer daar stagnasie plaasvind omdat daar 'n onwilligheid is om krities te evalueer, kan daar onbewustelik gaandeweg in 'n totaal verkeerde rigting beweeg word met ingrypende gevolge (Smith 2005a:46-57).

Die uiteindelike hermeneutiese sleutel kan gevind word in Filippense 1:9: 'Ook bid ek dat julle liefde al hoe meer sal toeneem in begrip en fyn aanvoeling, sodat julle die dinge sal kan onderskei waarop dit werklik aankom.' Alleen die Gees van God kan die insig en wysheid, gegrond in God se liefde, in die bedienaar en/of navorser werk om te begryp wat in die kinder- en jeugbediening moet gebeur (vgl. Heil 2010:46 n 22-25).

\section{Verrekening van metateoretiese aspekte rakende 'n wetenskapsteoretiese benadering tot kinder- en jeugbediening}

Uit die voorafgaande navorsingsresultate kan nou tot 'n eie definisie van die teologiese dissipline ${ }^{9}$ van Kinder- en jeugbediening gekom word. 'n Wetenskaplike omgaan met die werklikheid van kinder- en jeugbediening sou die volgende definisie as vertrekpunt kon neem:

Die prakties-teologiese dissipline, Kinder- en jeugbediening, is die wetenskaplike studie van die Woord van God, die kind en die jongmens, die werklikheid en ander toepaslike vakdissiplines, met die oog op die ontginning van die bybelse beginsels, en die ontwerp en die toepassing van ' $n$ bedieningsmodel met die doel om kinders en jongmense met die diakonia van die drie-enige God te bedien. Hierdie bediening vind plaas deur die kragtige werk van die Gees, om hulle tot persoonlikheidsgroei te begelei deur 'n dieper kennis van God en hulleself en tot geloofsgroei, wat hulle in staat kan stel om in 'n permanente verbondsverhouding met God te leef, hulle naaste in liefde te dien en die evangelie met hulle lewens uit te dra saam met ander gelowiges.

Met hierdie definisie word gepoog om die volgende aan te dui:

- Die Woord van God is die primêre bron van studie van Kinder- en jeugbediening. Sowel die gerigtheid as die inhoud van Kinder- en jeugbediening word deur die Woord bepaal.

- Kinder- en jeugbediening word deur bybelse beginsels bepaal.

- God is die handelende persoon in kinder- en jeugbediening. Kinder- en jeugbedienaars werk onder die diepe besef dat hulle kan saai en natmaak, maar dat die groei van God kom.

- Die studie van die kind en die jongmens, die werklikheid en ander vakdissiplines is gemik op die ontginning van bybelse beginsels vir die bediening van die mens.

- Navorsing behoort 'n bedieningsmodel daar te stel. Kinderen jeugbediening moet mense begelei tot die ontdekking van hulle identiteit in God drie-enig wat Hom aan hulle in hulle doop verbind het. Kinder- en jeugbediening behoort gestruktureerd volgens hierdie model aangepak te word en is nie 'n ongestruktureerde dobbelspel met allerlei nuwighede nie.

9.Kinder- en jeugbediening word as 'n selfstandige teologiese dissipline beskou. 
- Die primêre doel van navorsing in kinder-en jeugbediening is nie studie met die oog op die welwees van die kind en die jongmens nie, maar wel kennis- en geloofsgroei wat hulle verhouding met God sal verdiep en verinnig sodat daaruit vrede in alle omstandigheid kan voortvloei.

- Krisisse sal steeds deel van die kind en die jongmens se lewe bly, maar hulle sal dit deur die werk van die Gees en die waarheid van die Woord kan hanteer sodat daar telkens weer vrede in hulle lewens kom. Trauma, depressie, kommunikasie en alle onderwerpe wat krisisse in die mens se lewe kan veroorsaak, maak deel uit van die studieveld van Kinder- en jeugbediening. Hierin word aansluiting gevind by die pastoraat en ander vakdissiplines soos die Sielkunde, Kommunikasiekunde, Sosiologie en Opvoedkunde.

- Die eer van God behoort die hoogste doel van kinder- en jeugbediening en navorsing daaromtrent te wees. Die mens se welwees, geloofsgroei, vrede en vreugde word gesoek met die oog op hierdie hoogste doel.

- Navorsing in Kinder- en jeugbediening sal die kennis van ander toepaslike vakdissiplines ontgin as die openbaring van God in die skepping en dit aan die openbaring in die Woord toets en paslik integreer (vgl. Joubert 2005).

- Navorsing in Kinder- en jeugbediening is deel van die navorsing oor gemeentebediening en die pastoraat. Kinderen jeugbediening is die diakonia van die hele gemeente aan 'n deel van die gemeente wat in 'n sensitiewe tyd van hulle lewe verkeer. Hierdie lede moet dus besondere sorg ontvang (1 Kor 12).

- Die studie van die kommunikasiegebeure in kinder- en jeugbediening oorvleuel met die studievelde van die Pastoraat, Homiletiek, Kategetiek en Evangelistiek.

\section{Integrering van die verrekening van die metateoretiese aspekte ${ }^{10}$}

Figuur 1 ('Integrering van die verrekening van metateoretiese aspekte') is 'n visuele voorstelling en verklaring van die metateoretiese vertrekpunte waarmee 'n reformatoriese wetenskaplike die navorsingsterrein van Kinder- en jeugbediening behoort te benader ten einde die wetenskaplike taak uit te voer.

Die nege aanduidings kan soos volg beskryf word:

- Aanduiding 1: Die primêre bron van ondersoek in reformatories-wetenskaplike navorsing is die openbaring van God, eerstens in sy Woord maar ook in die skepping, onderhouding en regering van die werklikheid waarin ons leef. Kinder- en jeugbediening fokus primêr op die openbaring van God ten opsigte van sy diakonia aan die mens, wat deur die kerk aan die kinders en die jeug bedien moet word. God is met elke kind en jongmens besig en die bedienaars is slegs sy medewerkers wat biddend na die beste wyse moet soek om sy diakonia aan hulle te bedien in elkeen se unieke omstandigheid en binne die huidige milieu.

10.In'n vorige artikel (De Klerk et al. 2012) in die navorsingsprojek is intensief oor die noodsaak daarvan gehandel om metateoretiese vertrekpunte in die prakties-teologiese wetenskapsbeskouing en -beoefening te verreken.
- Aanduiding 2: Navorsers kom na die werklikheid met bepaalde vooronderstellings vanuit hulle geloofsoortuigings en kennis van die werklikheid. Hierdie vooronderstellings is voortdurend aan toetsing en vorming onderworpe soos die navorsers met God, sy Woord en die werklikheid omgaan.

- Aanduiding 3: Die Heilige Gees is met 'n voortdurende vormingsproses in die navorsers besig om hulle in die volle waarheid van die Woord, die Skepping en God se regering in die wêreld in te lei en so tot insig in die navorsingsproblematiek te bring. Die Gees werk ook tydens die aktiewe navorsing (vgl. Aanduiding 6).

- Aanduiding 4: Die navorsers se blik op die werklikheid vanuit hulle vooronderstellings bepaal ook hermeneutiese lense waardeur hulle na die navorsingsproblematiek gaan kyk, die ingesamelde data gaan prioritiseer en ontgin en daarna interpreteer.

- Aanduiding 5: Ten opsigte van die ondersoekveld van Kinder- en jeugbediening moet die navorsers vasstel watter velde hier belangrik is en wat die beskikbare inligting is wat is op kinder- en jeugbediening van toepassing is. Die integrering van hierdie inligting tot ' $n$ bedieningsplan is 'n belangrike stap in die navorsing.

- Aanduiding 6: Die metodiek van navorsing hang ten nouste saam met die vooronderstellings van die navorsers. Reformatoriese navorsers sal onder leiding van die Gees, biddend luister voor hulle praat. In die geval van kinderen jeugbediening sal dit vir die navorsers nodig wees om hulself in die leefwêreld van die kinders of jongmense in te leef en met priesterlike bewoënheid te luister. Daarna moet die versamelde data met wysheid ontleed word en die vraag na die grondoorsake van 'n situasie gevra word. Hierdie stap is in enige navorsing nodig sodat daar nie tot ' $n$ oppervlakkige oplossing gekom word wat slegs korttermynsukses kan gee nie. Die derde stap in die navorsing is om na die bybelse beginsels te vra. Hierdie is die beginsels waarop die bediening gebou moet word; beginsels wat onveranderd gehandhaaf kan word al is dit noodsaaklik om die bedieningsmetode en baie ander fasette van die bediening voortdurend aan te pas. Vanuit die ingesamelde data en die interpretasie daarvan moet op grond van die beginsels uit die Woord tot 'n eietydse aktuele en werkbare resultaat gekom word as 'n oplossing vir die navorsingsvraag.

- Aanduiding 7: Wanneer die volle spektrum van die kinder- en jeugbediening ondersoek is, moet tot 'n begronde bedieningsplan gekom word as deel van die totale bedieningsplan van 'n gemeente. Elke gemeente se bedieningsplan is uniek.

- Aanduiding 8: Die bedieningsplan moet daartoe lei dat die kinders deel kry aan die diakonia van Christus tot eer van die Vader deur die kragtige werk van die Gees. Hierdie diakonia dien tot opbou van die gemeente sowel as die uitbou van die gemeente wanneer die kinders gelowiges en ongelowiges met die liefde van Christus bedien. Die kinders word dus nie net bedien nie, maar word ook toegerus om te gaan bedien. Hierdie bediening vloei voort uit die liefde en oorgawe aan God wat in die kinders bewerk word wanneer elkeen individueel die diakonia van God in Christus deur die Gees ervaar. 


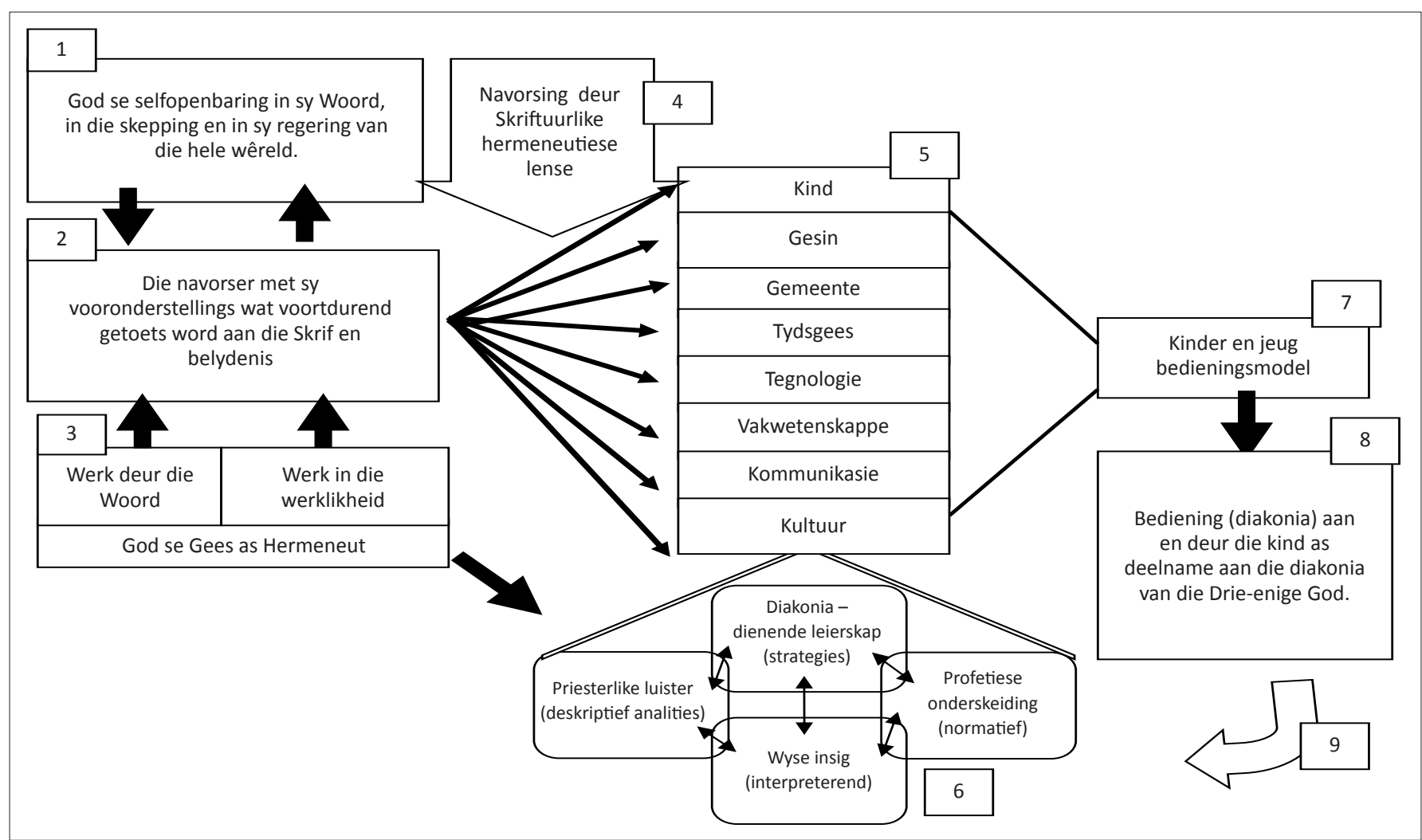

FIGUUR 1: Integrering van die verrekening van die metateoretiese aspekte.

- Aanduiding 9: Navorsers moet voortdurend herbesin oor elke faset van bediening. Nuwe vrae, nuwe omstandighede en nuwe tye moet telkens daartoe aanleiding gee dat die navorsingsproses van vooraf kan begin.

\section{Konklusie}

Die metateoretiese vertrekpunte van navorsers bepaal die primêre objek en metodiek van die navorsing. Hierdie vertrekpunte bepaal ook die verhouding tussen die navorsingsresultate vanuit die studie van die primêre navorsingsveld en die navorsingsresultate van oorvleuelende studievelde. Die werklikheidsbeskouing van die navorsers bepaal hulle benadering tot die hermeneuse, terwyl die hermeneutiese vertrekpunte en resultate weer 'n bepalende invloed op die wetenskaplike benadering tot navorsing het.

Navorsers wat hulle metateoretiese vertrekpunte uitspel, word daardeur gelei om aan hulle oortuigings getrou te bly en dit bewaar hulle van willekeur. Dit bring ook die lesers in die prentjie en gee hulle riglyne vir die hermeneutiese proses waarmee hulle in die bestudering van die navorsing besig is.

Vervolgens 'n voorbeeld hoe die metateoretiese onderbou 'n navorsingsprojek in kinder- en jeugbediening kan stuur.

\section{'n Beoordeling van die Gesins en jeugbedieningsmodel van Strommen en Hardel (2008)}

Wanneer 'n gemeente navorsing doen ten einde 'n bedieningsmodel vir die spesifieke behoeftes van daardie gemeente te vind, is dit noodsaaklik dat hulle verskillende modelle moet ondersoek en daaruit neem wat op hulle van toepassing is. Onder andere moet die vraag gevra word of 'n betrokke model die beginsels uit die Skrif, wat as hulle vooronderstellings geld, in daardie model eerbiedig. In hierdie artikel word die model van Strommen en Hardel (2008) aan die hand van bogenoemde reformatoriese beginsels beoordeel. Ten aanvang sal die inhoud van die model kortliks weergegee word, daarna sal die werklikheidsbeskouing, die hermeneutiese sleutels en die wetenskaplike benadering agtereenvolgens beoordeel word.

\section{'n Oorsig oor die model van Strommen en Hardel}

Strommen en Hardel (2008) stel hulle model vir gesins- en jeugbediening grafies voor in Figuur 2 ('Die model van Strommen en Hardel vir gesins en jeugbediening'). Die model sien die skepping, die kultuur, die gemeenskap, die gemeente en die huisgesin as die milieu waarin geloofsvorming moet plaasvind: 'Faith is formed by the Holy Spirit through personal, trusted relationships in all six of these areas.' [Geloof word deur die Heilige Gees gevorm deur persoonlike vertrouensverhoudings in al ses hierdie areas.] Die gesin beklee hierin die sentrale plek as die skakel tussen die kind en/of jongmens en die verskillende areas. Die gesin staan in venootskap met die ander vyf areas waarin die kinders en jongmense gevorm moet word (Strommen \& Hardel 2008:21).

Gesinsbediening vind op vier vlakke plaas: 'Strengthen family relationships' [Versterking van die gesinsbande], 'congregation as a family' [die gemeente as 'n familie], 'creating youth subculture' [die vorming van 'n jeugsubkultuur] en 'Faith 
focused Christian education' [geloofsgefokusde Christelike opvoeding] (Strommen \& Hardel 2008:14). Hulle definieer die begrip gesin breed. Gegrond op Jesus se woorde aan Maria en Johannes tydens sy kruisiging, naamlik 'Vrou daar is jou seun' en 'daar is jou moeder' (Joh 19:26, 27) huldig hulle die volgende oortuiging ten opsigte van die gesin: 'The church follows Christ by ensuring that no one in the family of faith is familyless - everyone is adopted into a family' [Die kerk volg Christus na deur te verseker dat niemand in die geloofsfamilie sonder ' $n$ familie is nie - almal word in ' $n$ familie opgeneem]. Hierdie stelling geld vir ' $n$ jonggetroude paartjie, maar ook vir paartjies wat nie kinders het nie.

Alle kinders en jongmense in die gemeente of almal wat moontlik betrokke wil raak, word aan' $n$ gesin in die gemeente verbind. Dit is duidelik dat persoonlike verhoudings waarin die kinders en jongmense veilig kan voel, 'n kardinale rol in hierdie model speel. Die onderlinge verhoudings binne die gemeente word in die eerste plek doelbewus uitgebou en versterk sodat die gemeente as 'n gesinseenheid kan funksioneer.

In die tweede plek word daaraan gewerk om die huisgesinne te versterk. Die huisgesin en die gemeente staan in 'n doelgerigte venootskap (Strommen \& Hardel 2008:15-164). Die gemeente is ' $n$ groot gesin wat uit verskillende kleiner gesinne bestaan. Die gemeente is betrokke by die gesin ten opsigte van pastorale, en indien nodig, ander versorging, toesig en toerusting. Die vertrekpunt van die gemeente is dat gesonde gesinne en huwelike 'n gesonde gemeente en gesonde kinders en jongmense tot gevolg het (Strommen \& Hardel 2008:30, 31). Die gesin word as die primêre opvoedingsinstelling gekoester en versorg. Die kerk het programme waarin daar gewerk word om die gesinsbande doelbewus te verinnig (Strommen \& Hardel 2008:51-61), ouers toe te rus om hulle kinders op te voed (Strommen \& Hardel 2008:62-75) en om vir hulle kinders geestelike leiers

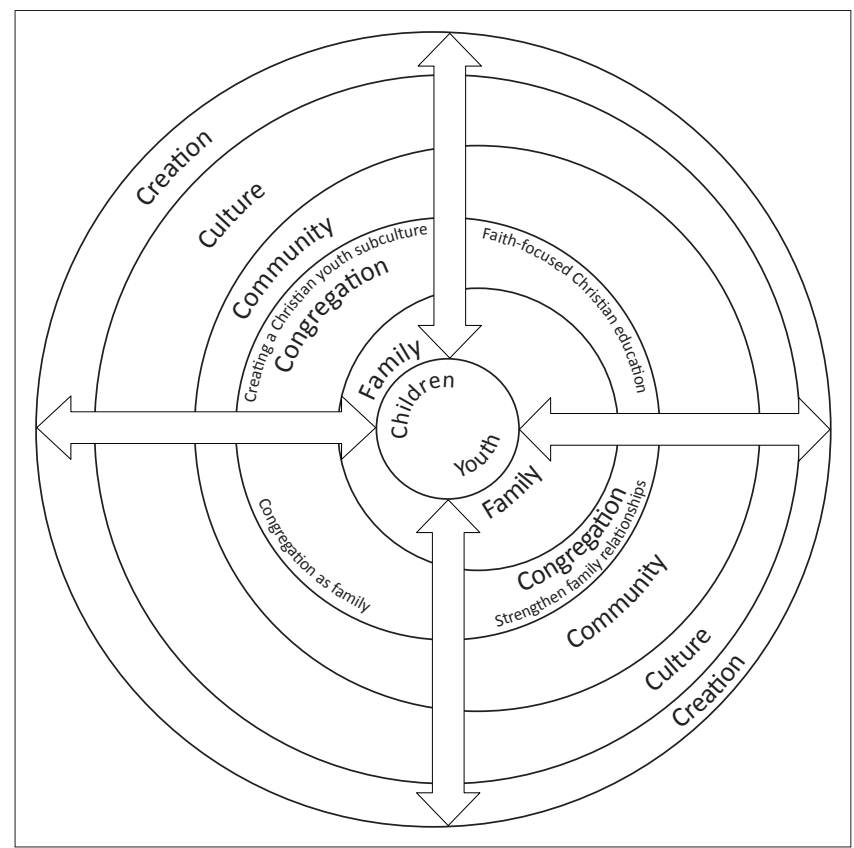

FIGUUR 2: Die model van Strommen en Hardel vir gesins en jeugbediening (Strommen \& Hardel 2008:23). te wees (Strommen \& Hardel 2008:31). Die gemeente moet haarself voortdurend evalueer of hierdie doelwitte bereik word (Strommen \& Hardel 2008:74, 75).

In die derde plek word sterk klem daarop gelê dat elke lidmaat in 'n lewende geloofsverhouding met God sal staan. Die uitgangspunt is dat die wedergeboorte en geloof wat deur die Heilige Gees gewerk word die mens tot 'n lewende geloof bring wat 'an affair of the hart and a commitment of the mind is that results in good actions' [' $n$ aangeleentheid van die hart en 'n verbintenis van die verstand is en wat goeie werke tot gevolg het] (Strommen \& Hardel 2008:84). Die plek van die gesin binne die oordrag en groei van die geloof ontvang deeglike aandag binne hierdie model. Daar word onder andere klem gelê op die gesprek met kinders binne die gesin waaruit die omgee vir mekaar duidelik blyk, asook die huisgodsdiens, die familieliturgie rondom die viering van spesiale dae en geleenthede en dienswerk (diakonia) waarby die gesin saam betrokke is. Hierdie klem sluit aan by die kategetiese onderrig waarin die Woord aan die kinders gebring word en waarby die ouers op verskeie maniere betrokke gemaak kan word. Die onderrig is daarop gerig dat die kinders en jongmense hulle vertroue vir hulle redding op Christus alleen plaas, God se genade begryp en uit hierdie genade biddend leef, morele verantwoordelikheid aanvaar en ook binne die gemeente verantwoordelikhede aanvaar, onbevooroordeeld en in liefde leef, gesag aanvaar en persoonlik vir hulle dade aanspreeklik gehou kan word, vol hoop positief leef, sinvol aan die liturgie van die gemeente deelneem en betrokke is by die uitdra van die evangelie ook deur dienswerk (Strommen \& Hardel 2008:112-163).

In die vierde plek is die kinder- en jeugbediening daarop gerig om binne die sekulêre kultuur waarin die kinders van dag tot dag leef, 'n alternatiewe Christelike kultuur te skep waarbinne groei kan plaasvind (Strommen \& Hardel 2008:195-236). Strommen en Hardel (2008:196) som die noodsaak hiervoor soos volg op:

When the culture of the nation no longer supports the Christian faith, a Christian youth subculture becomes a safe place for youth to discuss their questions and concerns about faith, to develop leadership skills, and to form relationships with other youth and caring adults. [Wanneer die kultuur van die nasie nie langer die Christelike geloof ondersteun nie, word 'n Christelike jeugsubkultuur' $n$ veilige hawe vir die jeug om hulle vrae en bekommernis oor godsdiens te bespreek, om leierskapsvaardighede te ontwikkel en om verhoudings te vestig met ander jeuglede en volwassenes wat omgee.] (bl. 1960, [outeur se eie vertaling])

In die vyfde plek word kinders en jongmense begelei om saam met die gemeente die wonder van die skepping te vier. Jongmense moet doelbewus begelei word om die skepping te geniet en God daarvoor te loof (Strommen \& Hardel 2008:296-315).

\section{Beoordeling van hierdie model vir'n reformatoriese kinder- en jeugbediening}

Uit die oorsigtelike studie van hierdie model moet drie vrae vervolgens beantwoord word. Is die model versoenbaar met die werklikheidsbeskouing, die hermeneutiese sleutels 
en die wetenskapsteoretiese benadering wat gebou is op die vooronderstellings van die reformatoriese wetenskapsbeoefening? Hierdie beskouings kom aan die orde in die uitdagings wat aan kinder- en jeug-bediening in die SuidAfrikaanse konteks gestel word.

\section{Is hierdie bedieningsmodel getrou aan die vooronder- stellings van die reformatoriese werklikheidsbeskouing?}

Die bedieningsmodel beklemtoon die volgende aspekte wat met die reformatoriese werklikheidsbekouing ooreenstem Die kinders en jongmense moet deur die gemeente bedien word; hulle is leerlinge wat binne gesonde gesinne behoort op te groei, gesinne wat nóú verbonde is aan die gemeente. Die een aspek wat nie eksplisiet in hierdie model 'n rol speel nie, is die verbond van God. Verskillende aspekte van die verbond soos die genade in Christus, die kinders en jongmense wat hulle identiteit in hulle verhouding met God moet vind en dat hulle begelei word om 'n lig vir die nasies te wees, word egter wel sterk beklemtoon. Wanneer hierdie model gebruik word, sou dit dus aangevul en verryk moet word met die verbondsperspektief vanuit die reformatoriese navorsing (vgl. De Wet \& Breed 2012).

\section{Is hierdie bedieningsmodel getrou aan die vooronderstellings van die reformatories-hermeneutiese benadering?}

Wat is die sleutels wat die werklikheid vir die navorsers kan oopsluit sodat hulle kan verstaan wat die beste wyse is waarop die kinders en die jongmense bedien kan word? Die vraag kan ook gevra word wat die bril is wat ons moet opsit sodat dit wat in die kultuur, die tydsgees, die ontwikkelingsvlak van die kinders, in die gemeente se situasie en baie ander faktore geskryf staan, ontsyfer en geïnterpreteer kan word. Uit watter hoek moet 'n mens kyk sodat die geïnterpreteerde feite weer saamgevoeg kan word tot 'n werkbare bedieningsplan? Die vraag wat nou beantwoord moet word, is of die samestellers van hierdie bedieningsmodel die regte interpretasie-instrument gebruik het.

Dit is in hierdie opsig waar die grootste tekortkoming in hierdie model geleë is. Die hermeneutiese sleutel wat gebruik is, is die vraag wat in kinder- en jeugbediening werk. Dit is moontlik dat 'n pragmaties-metateoretiese vooronderstelling onderliggend aan hierdie vertrekpunt lê. Die inligting waarop die model gebou is, is uit empiriese navorsing verkry wat by kerke gedoen is. Navorsing is gedoen om vas te stel by watter gemeentes daar suksesvolle kinder- en jeugbediening plaasvind. Daarna is gevra wat hierdie kerke doen om hierdie sukses te behaal. Op grond van die inligting wat so ingesamel is, is die model saamgestel (Strommen \& Hardel 2008:10, 11). Vir die reformatoriese navorser kan 'n empiriese studie baie nuttig wees om bepaalde tendense uit te wys. Die feite wat so verkry word, dwing die navorser egter terug na die Skrif. Dit wat uit die studie afgelei word, moet aan die Skrif getoets word, maar dit kan ook die navorser se oë oopmaak om die Skrif weer nuut te verstaan.
Strommen en Hardel (2008) gee nie in die beskrywing van hulle model blyke dat hulle die inligting wat uit die empiriese navorsing verkry is, weer met die Skrif vergelyk het nie. Hulle maak gebruik van die suksesvolle bedieningstrategieë van gemeentes. Waarskynlik het hierdie gemeentes hulle optrede op die Woord gegrond soos in die paragraaf, 'Is hierdie bedieningsmodel getrou aan die vooronderstellings van die reformatoriese werklikheidsbeskouing?', duidelik geword het. Indien 'n navorser Strommen en Hardel se model vir reformatoriese kerke wil bruikbaar maak, is dit belangrik om die resultate wat in die model neerslag vind aan die Skrif te toets, dit te begrond en aan te pas.

'n Tekortkoming in die model is die gebrekkige klem op die leiding van die Gees. Die Gees gee insig en wysheid; die Gees verander harte en maak 'n model bruikbaar. Die Gees lei die navorser na nuwe insigte en vernuwing.

\section{Is hierdie bedieningsmodel getrou aan die vooronder- stellings van die reformatories-wetenskapsteoretiese benadering tot kinder- en jeugbediening?}

Wanneer op 'n wetenskaplike wyse navorsing gedoen word, is dit belangrik dat Kinder- en jeugbediening duidelik gedefinieer word. Uit sodanige definisie is die vooronderstellings waarvolgens die navorsing gedoen word duidelik, naamlik om by 'n wetenskaplike teorie uit te kom. Vanuit die teorie kan na die praktyk beweeg word sodat 'n gesonde wisselwerking tussen die teorie en die praktyk van stapel gestuur kan word.

In Figuur 1 is die proses van wetenskaplike navorsing op grond van die reformatoriese metateorie uiteengesit. Dit hou in dat God erken word as die groot Herder van die kudde. Dit is sy diakonia wat aan die kinders en die jongmense bedien moet word. Die reformatoriese navorser werk onder die diepe besef dat die insig en die wysheid van die Gees moet kom en dat die hermeneutiese sleutels waardeur die werklikheid ontsluit moet word deur sy blik op die werklikheid, vanuit die Skrif, bepaal word. Die reformatoriese navorsing kan met vrug die metodiek van Osmer (2008) gebruik. Hiervolgens word daar op vier maniere na die werklikheid gekyk. Met priesterlike bewoëndheid word geluister om te verstaan wat in die werklikheid aangaan; met wysheid moet gevra word na die redes agter die huidige toestand; met profetiese insig moet die beginsels uit die Bybel wat op die problematiek van toepassing is, ontgin word sodat dit duidelik kan word wat behoort te gebeur en uiteindelik moet by 'n werkbare oplossing uitgekom word. Hieraan beoordeel, is dit duidelik dat Strommen en Hardel (2008) op 'n wetenskaplikverantwoordbare wyse navorsing gedoen het ten opsigte van wat in die werklikheid van kinder- en jeugbediening aangaan. Hulle het ook die oorsaaklike vraag beantwoord waarom die huidige situasie in die kinder- en jeugbediening is wat dit is. Die resultate van die antwoorde op hierdie twee vrae het hulle gebruik om by 'n oplossing uit te kom. Wat hulle nie beantwoord het nie, was hoe die resultate van hulle empiriese ondersoek in die lig van die Skrif beoordeel moet word. 'n Diepgaande Skrifondersoek was nodig om hierdie vraag te beantwoord. 


\section{Konklusie}

Die gemeente of reformatoriese navorser wat Strommen en Hardel se model in die Suid-Afrikaanse konteks wil gebruik, moet deur middel van 'n eksegetiese studie die bevindings waarop die model gebou is aan die Skrif toets en begrond en in die unieke uitdagings van die Suid-Afrikaanse konteks laat grondvat. Die betekenis van die verbond vir hierdie model moet ook nagevors word en die model moet met die bevindings daarvan verryk word.

\section{Erkenning Mededingende belange}

Die outeur verklaar dat hy geen finansiële of persoonlike verbintenis het met enige party wat hom nadelig kon beïnvloed het in die skryf van hierdie artikel nie.

\section{Literatuurverwysings}

Anderson, R.S., 1964, Like living stones, WIPF \& Stock, Eugene.

Anderson, R.S., 2001, The shape of practical theology: Empowering ministry with theological praxis, IVP Academis, Downers Grove.

Anderson, R.S., 2007, Something old, something new: Marriage and family ministry in a postmodern culture, Wipf \& Stock, Eugene.

Barrett, P.J, 2000,. 'Toward a trinitarian "theory of everything"', in C.W. du Toit (ed.), Evolution and creativity: A new dialogue between faith and knowledge, pp. 303-329, Research Institute for Theology and Religion, Pretoria.

Benett, A., 2011, 'The continuing importance of the "cultural" in the study of youth" [Die voortgaande belang van die kulturele aspek in die studie van die jeug], Youth [Die voortgaande belang van die

Berding, K., 2006, What are spiritual gifts?: Rethinking the conventional view, Kregel, Grand Rapids.

Blount, R., 2005, 'In search of living waters: The seven spiritual yearnings of youth', in The Princeton lectures on youth, church and culture, pp. 1-10, The Institute for Youth Ministry, Princeton Theological Seminary, Princeton.

Breed, G., 1994, 'Kategese en geloofsopvoeding', ThD-verhandeling, Fakulteit Teologie PU vir CHO, Potchefstroom

Breed, G., 1996, 'Sien, hoor en ken: Basisteoretiese perspektiewe op geloofsopvoeding deur die onderhouding van die Pasga - 'n verkenning van Ou-Testamentiese gegewens', In die Skriflig 30(1), 57-72.

Breed, G., 2012a, 'Nuut gedink oor die wese en inhoud van die dienswerk van die diaken', Hervormde Teologiese Studies 68(1), 1-17. http://dx.doi.org/10.4102/hts.v68i1.1059

Breed, G., 2012b, The preacher as diakonos according to John 12:26, Ongepubliseerde referaat gelewer by die konferensie van Sociatas Homiletica, 2012 te Wittenberg.

Breed, G. \& Breed, D.G., 2010, 'Besinning oor die diakonale dienswerk na aanleiding van Handelinge 6:1-7', In die Skriflig 44(3 \& 4), 627-653.

Brueggemann, W., 2001, Deuteronomy, Abingdon, Nashville, (Old Testament Commentaries).

Bunge, M.J., 2008, 'Biblical and theological perspectives on children, parents, and "best practices" for faith formation: Resources for child, youth, and family ministry today'

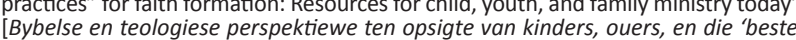
Bybelse en teologiese perspektiewe ten opsigte van kinders, ouers, en die 'beste
praktyke' vir geloofsvorming: Hulpmiddels vir kinder-, jeug- en gesinsbediening praktyke' vir geloofsvorming: Hulpmiddels vir kinder-,
vandag], Dialog: A Journal of Theology 47(4), 348-360.

Collins, R.F. \& Harrington, D.J., 1999, First Corinthians, Liturgical Press, Minnesota.

Colson, C. \& Pearcy, N., 1999, Developing a Christian worldview of the Christian in today's culture, Tyndale, Wheaton.

De Klerk, B., De Wet, F. \& Pieterse, H.J.C., 2012, 'Die noodsaak daarvan om metateoretiese vertrekpunte in prakties-teologiese wetenskapsbeskouing en -beoefening te verreken', In die Skriflig/In Luce Verbi 46(1), 11 pages.

De Wet, F.W., 2011, 'Die noodsaak daarvan om metateoretiese vertrekpunte ten opsigte van werklikheidsbeskouing in praktiesteologiese wetenskapsbeoefening uit te spel', In die Skriflig 45(1), 1-23. http://dx.doi.org/10.4102/ids.v45i1.2

De Wet, F.W. \& Breed, G., 2012, 'Entrance into the covenantal space as point of departure for the liturgical act of living the baptismal life in this world' [Intrede in die verbondsruimte as vertrekpunt vir die liturgiese daad van die lewe as 'n gedoopte in die wêreld], NGTT 53(3 \& 4), 1-18.

Dean, K., Martison, R., Nishioka, R., Rounds, D.G., Vaughn, A.S. \& Corotta, M., 2010, OMG: A youth ministry handbook, Abindon, Nashville.

DeVries, M., 2004, Family based youth ministry, InterVarsity, Downers Groove.

DeVries, M., 2008. Sustainable youth ministry: Why most youth ministry doesn't las and what your church can do about it, InterVarsity, Downers Groove.

Dreyer, J.S., 2004, The research challenge: Doing empirical research in theology, Only study guide for CMM305-X, University of South Africa, Pretoria.
Dingemans, G.D.J., 1996, Manieren van doen - inleiding tot de studie van de praktische theologie, Kok, Kampen.

Grobbelaar, J., 2008, "n Ondersoek na die bediening van laerskoolkinders in en deur die gemeente as intergenerasionele ruimte', ThD-proefskrif, Fakulteit Teologie, Universiteit van Stellenbosch, Stellenbosch.

Hastings, T., 2007, Practical Theology and the one Body of Christ: Toward a missionalecumenical model, Eerdmans, Grand Rapids.

Hayler, P., 2006, Response to Paula Gooder's paper on the scholarship of John N. Collins, Paper presented at the Communion of the Porvoo Churches Consultation on the Diaconate, 25-27 January 2006, the Royal Foundation of Saint Katharine London, viewed 10 February 2010, from http://www.porvoochurches.org/last4years/ london.html

Heil, J.P., 2010, Philippians: Let us rejoice in being conformed to Christ, Society of Biblical Literature, Atlanta.

Hoehner, H., 2002, Ephesians: An exegetical commentary, Baker Bookhouse, Grand Rapids.

Hunt, G., Moloney, M. \& Evans, K., 2009, 'Epidemiology meets cultural studies: Studying and understanding youth cultures, clubs and drugs' [Epidemiologie in kultuurstudie: Die bestudering en verstaan van jeugkulture, klubs en dwelms], Addiction Research and Theory 17(6), 601-621. http://dx.doi.org/10.3109/16066350802245643, and Theory 17(6), 601-621. http:

Joubert, P., 2005, 'Trichotomous therapy: A proposed pastoral paradigm', 'PhD thesis, Faculty of Theology, North West University, Potchefstroom.

Kruger, S.F., 2005, 'Toerusting as wordingsproses: Perspektiewe uit die Efesiërbrief', In die Skriflig 39(3), 527-553. http://dx.doi.org/10.4102/ids.v39i3.401

Marty, M.E., 2007, The mystery of the child, Eerdmans, Grand Rapids.

Mueller, W., 2006, Engaging the soul of youth culture: Bridging teen worldviews and christian truth, IVP Books, Downers Grove.

Mueller, W., 2007, Youth culture 101, Zondervan, Grand Rapids.

Newport, J.P., 1998, The New Age movement and the biblical worldview: Conflict and dialogue, Eerdmans, Grand Rapids.

Noordegraaf, A., 1991, Theologie in reformatorish perspectief: Oriëntatie in het diakonaat, Boekenzentrum, Zoetemeer.

Pieterse, H.J.C., 2011, 'Die noodsaak van die verrekening van metateoretiese aspekte rakende' $n$ hermeneutiese benadering tot die Praktiese Teologie', In die Skriflig 45(4) 719-737. http://dx.doi.org/10.4102/ids.v45i4.200

Purves, A., 2004, Reconstructing pastoral theology: A christological foundation, Westminister John Knox Press, Louisville.

Reeder, H.L., 2008, From embers to flame: How to revitalize your church, P\&R Publishing Phillipsburg.

Richards, L.O., 1983, A theology of children's ministry, Zondervan, Grand Rapids.

Richards, L.O. \& Martin, G., 1981, A theology of personal ministry: Spiritual giftedness in the local church, Zondervan, Grand Rapids.

Robbins, D., 1990, The ministry of nurture - a youth worker's guide to discipling teenagers, Grand Rapids, Zondervan.

Robbins, D., 2004, This way to youth ministry: An introduction to the adventure, Zondervan, Grand Rapids.

Sell, P.W., 2010, 'The seven in Acts 6 as a ministry team', Bibliotheca Sacra 167(1), 58-67.

Senter, M.H., 2010, When God shows up: A history of protestant youth ministry in America, Baker Academic, Grand Rapids.

Smith, C., 2005a, 'On "moralistic therapeutic deism" as U.S. teenagers actual, tacit, de facto religious faith', in The Princeton Lectures on Youth, Church and Culture, pp. 46-58, The Institute for Youth Ministry, Princeton Theological Seminary, Princeton. http://dx.doi.org/10.1093/acprof:oso/9780195371796.001.0001

Smith, C., 2005b, 'Implication of national study for youth and religion findings for religious leaders, faith communities and youth workers', in The Princeton Lectures on Youth, Church and Culture, pp. 59-68, The Institute for Youth Ministry, Princeton Theological Seminary, Princeton.

Smith, C. \& Snell, P., 2009, Souls in transition, Oxford University Press, Oxford.

Strommen, M.P. \& Hardel, R.A., 2008, Passing on the faith: A radical model for youth and family ministry, Saint Mary's Press, Winona.

Tripp, P.D., 1997, Age of opportunity, Presbyterian \& Reformed Press, Phillipsburg.

Veerman, D., 1997, 'How can leaders build a relational youth ministry?', in R.R. Dunn \&. M.H. Senter (eds.), Reaching a generation for Christ: A comprehensive guide to youth ministry, pp. 218-238, Moody Publishers, Chicago.

Van der Merwe, C.N., 2004, 'Kategese as middel tot heilsekerheid en heilstoeeiening in die konteks van die verbond en die koninkryk', PhD-proefskrif, Fakulteit Teologie, NWU, Potchefstroom.

Vos, J.S., 1993, 'Das Rätsel von 1 Kor 12:1-3', [Die raaisel van 1 Kor 12:1-3], Novum Testamentum 35(3), 251-269. http://dx.doi.org/10.1163/156853693X00167

Vukich, L. \& Vandegriff, S., 2002, Timeless youth ministry: A handbook for successfully reaching today's youth, Moody Press, Chicago. PMid:12458860

Wolters, A.M., 2005, Creation regained: Biblical basics for a reformational worldview, 2nd edn., Eerdmans, Grand Rapids.

Wyn, J., 2011, 'The sociology of youth: A reflection on its contribution to the field and future directions' [Die sosiologie van die jeug: ' $n$ besinning ten opsigte van die bydrae tot die navorsingsveld en toekomsaanwysers], Youth Studies Australia 30(3), 34-39. 